
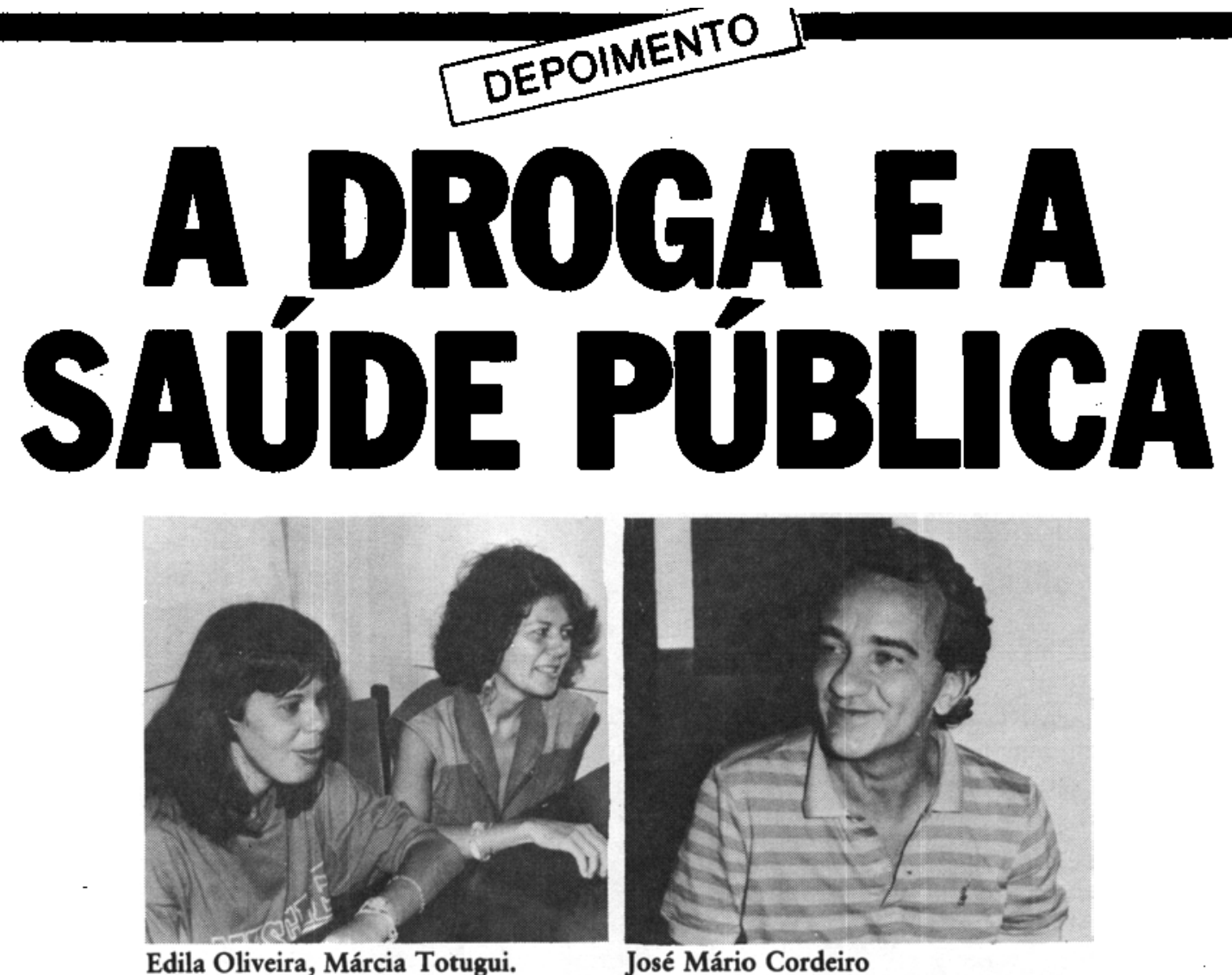

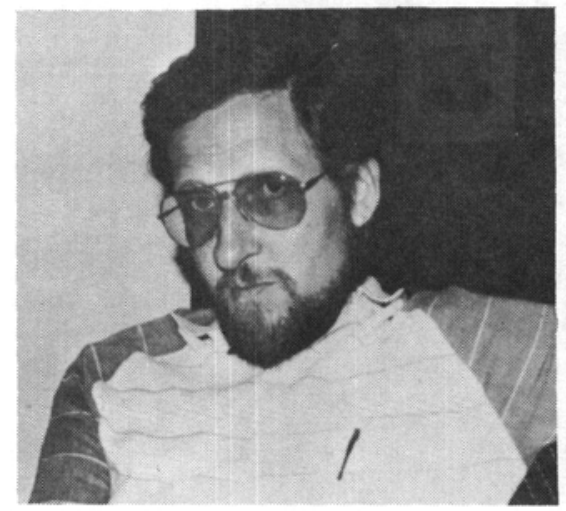

Richard Bucher

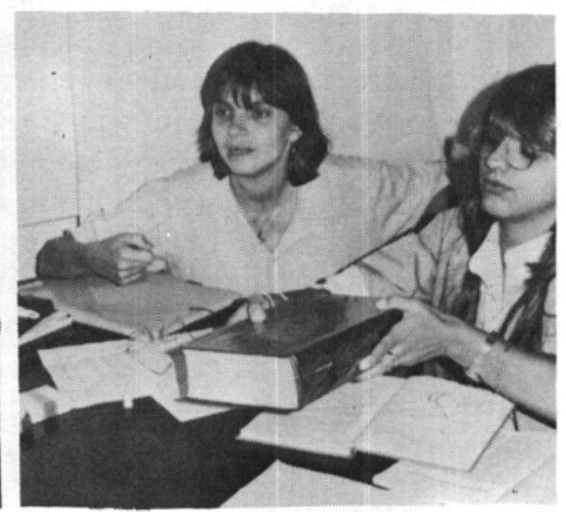

Ana C. Lustosa, Sônia Amaral.

O uso de drogas é um assunto que não sai da ordem do dia. Está presente nos meios de comunicaçāo de massa, nos diálogos dos pais com filhos, nas açōes das autoridades praticadas em nome

da Lei, enfim em diferentes momentos e lugares da vida cotidiana. Sobretudo os meios de comunicaçao de massa que costumam alardear como perigosas somente as drogas consideradas ilícitas, a maconha $\theta$ a cocaína. Entretanto, as drogas lícitas (álcool, fumo,medicamentos etc) não são alvo de alerta na mesma proporção da gravidade em que se constituem como um problema de saúde pública. Esta é uma das conclusões,

da equipe multiprofissional do Centro de Orientação sobre Drogas e Atendimento a Toxicómanos (CORDATO).

Participaram deste Depoimento os seguintes membros da equipe: o psiquiatra José Mário Cordeiro, o psicanalista Richard Bucher, as psicólogas Márcia Totugui, Sônia M. B. Amaral, Elizabeth Costa, Ana Carolina Lustosa e a enfermeira Edila Oliveira. 
O Centro de Orientação Sobre Drogas e Atendimento a Toxicômanos (CORDATO) foi inaugurado oficialmente em abril de 1986, contando com o apoio da Universidade de Brasília (UnB) e do Conselho Federal de Entorpecentes (CONFEN), órgão do Ministério da Justiça. Seis meses mais tarde, passou a receber também o apoio da Secretaria de Saúde do Distrito Federal. E hoje funciona como uma atividade de extensảo, a nível de ação comunitária, e de pesquisa do Departamento de Psicologia da UnB.

\section{A equipe multiprofissional}

Tratando-se de uma entidade que busca um modelo alternativo de atendimento a toxicômanos, o CORDATO decidiu inovar também no relacionamento interno de sua equipe. Esta é composta por 8 psicólogos, 4 psiquiatras, 1 enfermeira e 1 assistente social, que trabalham como equipe multiprofissional, com a proposta de que funcione sem hierarquia determinada pelas profissões, pois a coexistência de profissionais de diferentes áreas é muitas vezes prejudicada pela questão do corporativismo.

O psiquiatra José Mário Simil Cordeiro declarou como o corporativismo pode deixar de ser predominante na interação da equipe: "Quando a instituição atua com profissionais de diferentes áreas e tem um projeto comum, isto nivela os objetivos da equipe. A solução dos conflitos corporativistas é possível, justamente, através de uma identificação com esse projeto".

\section{A necessidade de pesquisa}

Como há poucas pesquisas científicas que possam fornecer dados confiáveis a respeito do uso e abuso de drogas no Brasil, o CORDATO realizou como uma de suas primeiras atividades uma pesquisa, no âmbito do Distrito Federal, justamente para melhor direcionar seu trabalho. O levantamento é de caráter regional, já que foi aplicado apenas em escolas públicas de Brasília. Foram ouvidos alunos do $1^{\circ} \mathrm{grau}$, entre 13 e 14 anos; do $2^{\circ}$ grau, com 16 anos; e universitários, do ciclo básico. $\mathrm{O}$ objetivo desta pesquisa era investigar os conhecimentos sobre drogas e caracterizar o uso de 6 PSICOLOGIA, CIENCIA E PROFISSÃO drogas, lícitas ou ilícitas - entre elas, - cigarro, o álcool, a maconha, a cocaína, medicamentos, estimulantes, tranquüilizantes, hipnóticos, alucinógenos, entre outros. A pesquisa abordou o aspecto das fontes de abastecimento, em que idade a droga foi usada pela primeira vez, qual a fonte de informaçōes, as motivações que levaram à experiência com drogas, e qual a opinião dos usuários sobre $o$ assunto. Todo o trabalho foi baseado num questionário que a Organização Mundial de Saúde já aplicara em sete países.

\section{Álcool, fumo e medicamentos}

Os resultados desta pesquisa apontaram o álcool e o fumo como as drogas mais consumidas. Em segundo lugar, os medicamentos. Em terceiro, os inalantes (cola de sapateiro, lolo, lança-perfume). Em quarto lugar, a maconha.

De acordo com o psicanalista Richard Bucher, foram resultados que entraram cm contradição com as informações veiculadas pela imprensa em geral. A respeito desse problema, o psiquiatra José Mário declarou: "De acordo com esta nossa pesquisa, a maconha não é um problema grave no Brasil. Talvez pudéssemos dizer que os dados que apontam esta droga como problema mais sério, na verdade, estariam desviando a atenção da questão dos medicamentos. Estes é que constituem o grande problema da toxicomania no Brasil. Um problema agravado pela participação da categoria médica que, com certa irresponsabilidade, busca (e receita) medicamentos que comprovadamente provocam dependência".

Uma questão grave é que muitas vezes são os próprios pais - geralmente desinformados e com uma visão superdramatizada a respeito de drogas - que, juntamente com os médicos, influenciam seus filhos a consumirem medicamentos, sobretudo os tranqüilizantes. "Prescrever tranqüilizantes para jovens e crianças é abrir uma porta para o futuro abuso de drogas", avisa Richard Bucher.

\section{Muito alarde,pouca intormaçăo}

A pesquisa também mostrou que os alunos têm mais informações sobre 0 assunto do que os professores. São informações de origem duvidosa, pois provêm principalmente dos meios de comunicação - de caráter sensacionalista - ou então de conversas com amigos. Por isso, uma das conclusões da equipe é que este segmento está carente de informaçōes precisas e mais objetivas sobre os problemas que a droga pode causar.

A distinção entre usuário e toxicômanos, utilizada pelo CORDATO desde sua inauguração, foi perfeitamente justificada pelos resultados da pesquisa. Os toxicômanos e os quase toxicômanos dependem da droga a ponto de precisarem consumi-la quase diariamente.

Uma outra distinção entre o perfil dos usuários e o dos toxicômanos é a diferença de idade. Os dependentes têm por volta de 25 a 30 anos. Os usuários geralmente são adolescentes, e comparecem ao CORDATO levados pelos pais. "No caso destes adolescentes, fica muito claro que o mais importante é orientar a família para que converse com o jovem, buscando diálogo. Sem recorrer à violência ou à sua exclusão da família, mas assumindo uma posição intermediária entre a repressão cega e o falso liberalismo", afirma Richard Bucher.

\section{Um modelo alternativo de tratamento}

A proposta de trabalho prioritário do CORDATO é a prestação de serviços: "Em primeiro lugar, somos uma instituição especializada no acolhimento de toxicômanos e usuários de drogas", afirma o psiquiatra José Mário. E foi com esse trabalho que a entidade chegou a contabilizar, em menos de um ano de atividade, a cifra de 140 casos, totalizando cerca de 700 atendimentos.

A concepção do trabalho do CORDATO baseia-se, em linhas gerais, na abordagem psicanalítica. Esta é também a base do trabalho do doutor Claude Olivenstein, no Hospital Marmottan, sediado em Paris, embora este não seja um centro de psicanálise. Ali se desenvolve a concepção de toxicomania no sentido de se indentificar um sintoma, relacionado com a vida do usuário,que indique outros conflitos subjacentes no uso de drogas. Dentro desta concepção, o trabalho do CORDATO vem se desenvolven- 


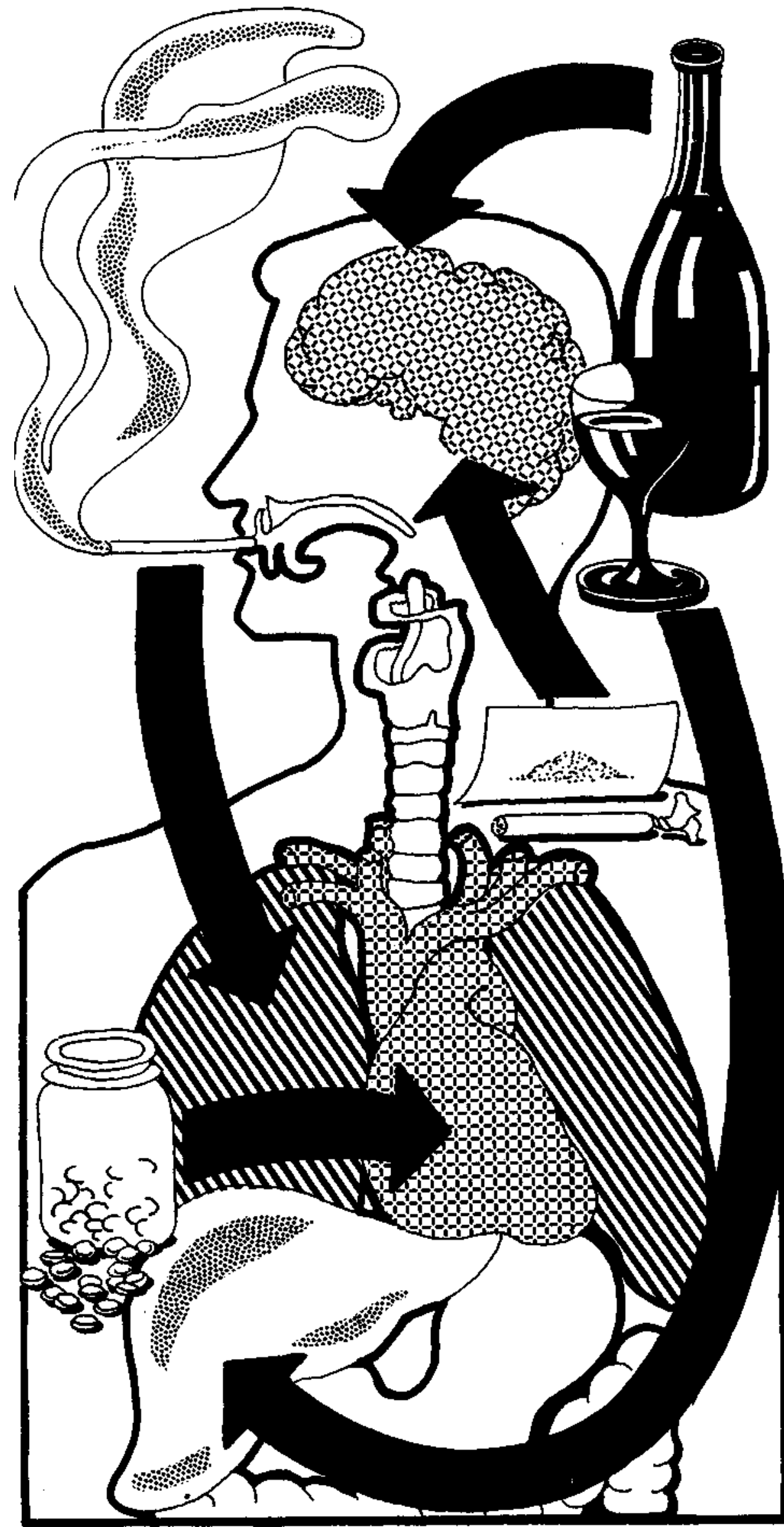

do como uma procura de um modelo alternativo de atendimento ao toxicómano. Não se quer, de modo algum, atuar no nivel filantrópico. A intenção é questionar o usuário de drogas para tentar levá-lo a se responsabilizar por seus atos.

\section{A voluntariedade e}

\section{o direlto ao anonimato}

As formas de encaminhamento terapêutico a serem adotadas para os usuários de drogas são bastante similares às adotadas para os toxicômanos. Nos dois casos, o cliente recebe orientação e, dependendo da necessidade de cada um, pode ser encaminhado para um tratamento psicoterá. pico mais específico. Se o cliente estiver acompanhado dos pais, estes também receberão uma orientação particular e adaptada aos seus problemas.

Nós respeitamos a regra da voluntariedade", declara José Mário. "Só sảo aceitos para terapia aqueles que concordam com este procedimento. Só acreditamos em psicoterapia quando esta responde à demanda do paciente." Uma das tarefas do CORDATO é justamente promover o surgimento desta demanda pelo tratamento, que é vivida inicialmente de forma mais intensa pela família do que pelo usuário.

Outras características do atendimento dado pelo CORDATO são os princípios de gratuidade e de neutralidade religiosa e o direito ao anonimato, garantidos a todos os clientes. $\mathrm{O}$ direito ao anonimato é importante, porque muitos chegam à entidade com desconfiança de que serão denunciados à polícia. "Na verdade, as autoridades policiais nos respeitam", diz o doutor Richard. "Mas recebemos pressöes por parte de famílias que querem saber se seus filhos comparecem às consultas. E uma questão delicada, pois não podemos dar estas respostas."

\section{Uma terapla a longo prazo}

Basicamente, o tratamento do toxicômano passa por três fases, explica o psiquiatra José Mário. "A primeira é um processo de desintoxicação, feito por um período de no máximo dez dias numa enfermaria. Como o CORDATO não tem acomodações para internação, no único caso em que a

PSICOLOGIA, CIĖNCIA E PROFISSÄO 7 
internação foi necessária, utilizou-se um hospital psiquiátrico.

$A$ segunda fase $\varepsilon$ a avaliação para se definir qual é a melhor direção que pode ser dada à terapia. Nessa fase, deve ocorrer uma convivência maior com a equipe terapêutica, que possibilite o surgimento de uma demanda autêntica de psicoterapia. Para a equipe isso traria a oportunidade de conhecer aspectos concretos de sua vida como, por exemplo, o fato de ele estar sem trabalhar, afastado da escola, desvinculado da família etc. E a terceira fase é a terapia propriamente dita, embora ele tenha começado desde o primeiro contato do toxicômano com a entidade.

"A nossa conviç̧ão $\varepsilon$ que o problema do toxicômano requer uma terapia a longo prazo", diz o professor Richard. "Não acreditamos em terapias rápidas. $O$ verdadeiro dependente de drogas tem características de instabilidade quanto a querer, ou não, parar com o consumo." Essa instabilidade do dependente de drogas e a dificuldade em manter uma regularidade de comportamento caracterizam um aspecto peculiar ao trabalho do terapeuta. "Nossa preocupação enquanto terapeuta é estabelecer um vínculo forte para que o dependente possa ter uma referência constante, apesar das oscilações e da ambigüidade que mantém com o terapeuta e com a instituição. Estas oscilaçōes podem ser entendidas pelo fato de ele transgredir a lei quando consome drogas ilegais, porém ao estabelecer uma relação com o terapeuta $\mathrm{e}$ com a instituição, realiza-se um compromisso com a lei que não é a jurídica e sim a representante dos limites da convivência social", declarou Richard Bucher.

As angústias dos profissionals

$A$ área de toxicomania tem sido considerada maldita dentro da Psiquiatria. Estes pacientes são considerados incuráveis, rejeitados, marginalizados. Para eles a Psiquiatria tem oferecido o modelo repressivo, próximo do policial. No entanto, a experiência do CORDATO tem mostrado, para sua equipe, que vale a pena procurar outras saídas, e enfrentar com disposição diferente as angústias profissionais perante as oscilações destes

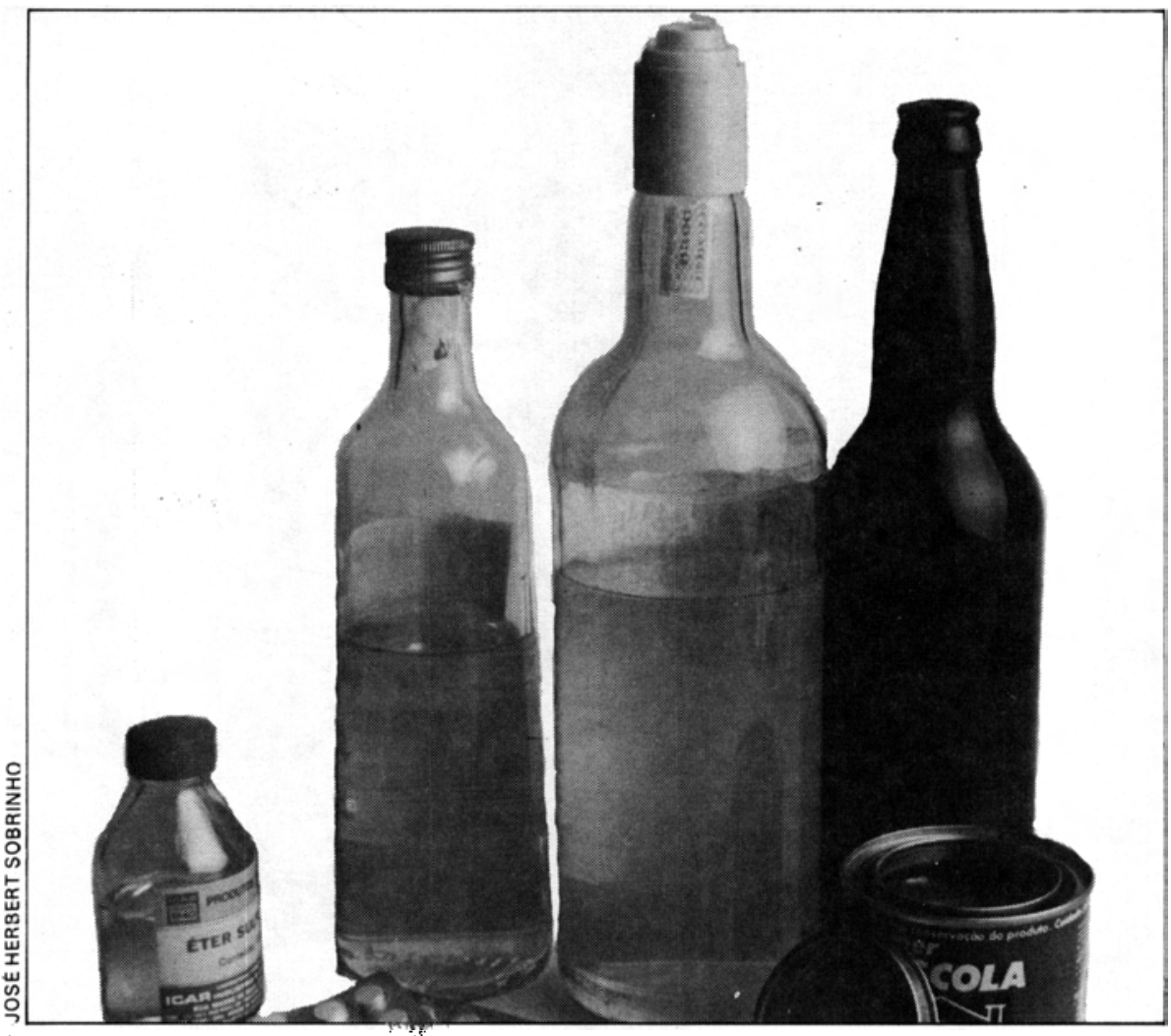

pacientes. José Mário afirma: "Tenho observado que é fundamental aprender a esperar, aprender a cultivar a situação terapêutica sem a pretensão e a impulsividade da cura. Aprendi no CORDATO que precisamos renunciar a essa pretensão imediatista de cura - uma influência que o médico recebe da escola - para que a gente possa, inclusive, ter espaço para trabalhar. Não é uma renúncia fácil. Como profissional, como pessoa e como terapeuta, a gente quer teimosamente cultivar essa ilusão da onipotência da cura, querendo de alguma maneira ter resultados imediatos. Mas isso é uma ilusão. A questão da urgência está fora do esquema do trabalho com o drogado. Como diz o doutor Olivenstein, nós temos que aprender a esperar. E urgente saber esperar. Ter esperança e aguardar".

\section{$O$ trabalho preventivo}

Além de desenvolver pesquisas e atendimento terapêutico, o CORDATO também realiza um amplo trabalho preventivo. A entidade já promoveu cursos destinados a professores, na Fundação Educacional do Distrito Federal e nas escolas particulares. "Esses cursos não se restringem a enfocar a questão da droga e os perigos a que ela expōe os seus usuários", conta a psicóloga Ana Carolina Linhares Lustosa. "Não são simples cursos de toxicologia. Eles abordam o problema dentro de um contexto maior: a questão da família, da sociedade, aspectos da motivação, os problemas da adolescência, uma visão histórica, antropológica e jurídica da questão da droga. Isso sensibiliza mais as pessoas a se questionarem e participarem da discussão do problema."

A equipe psicopedagógica do CORDATO,responsável pelas atividades preventivas, está com uma programação extensa para ser realizada em 1987. Diversos cursos estão sendo oferecidos: curso de informação e formação para professores da Fundação Educacional do Distrito Federal; curso de informação e treinamento para as diversas equipes de saúde da Fundação Hospitalar do Distrito Federal; cursos de informação e treinamento nos Centros de Desenvolvimento Social da Fundação de Serviços Sociais.

o CORDATO tem um plantão permanente, das nove da manhã às nove da noite, e atende também pelo telefone (061) 272-4555. Endereço: CLN 205 - Bloco D, sobreloja 7 Brasília, DF. CEP 70843. 